\title{
Should reproductively isolated populations of Lutzomyia longipalpis sensu lato receive taxonomically valid names?
}

\author{
Sinval P Brandão-Filho' $/^{+}$, Valdir Q Balbino², Carlos B Marcondes ${ }^{3}$, Reginaldo P Brazil ${ }^{4}$, \\ James G Hamilton ${ }^{5}$, Jeffrey J Shaw $/{ }^{+}$

\begin{abstract}
${ }^{1}$ Instituto Aggeu Magalhães-Fiocruz, Av. Moraes Rego s/n, 50670-429 Recife, PE, Brasil ²Departamento de Genética, Centro de Ciências Biológicas, Universidade Federal de Pernambuco, Recife, PE, Brasil ${ }^{3}$ Departamento de Microbiologia, Centro de Ciências Biológicas, Universidade Federal de Santa Catarina, Florianópolis, SC, Brasil ${ }^{4}$ Laboratório de Bioquímica e Fisiologia de Insetos, Intituto Oswaldo Cruz-Fiocruz, Rio de Janeiro, RJ, Brasil ${ }^{5}$ Centre for Applied Entomology and Parasitology, Institute of Science \& Technology in Medicine, Keele University, United Kingdom ${ }^{6}$ Departamento de Parasitologia, Instituto de Ciências Biomédicas, Universidade de São Paulo, São Paulo, SP, Brasil
\end{abstract}

A group of 18 research workers involved in different aspects of the biology of Lutzomyia longipalpis discussed whether or not it is important to give taxonomically valid names to populations that have been defined by biological, biochemical and molecular methods to be reproductively isolated. The type material of this medically important species has been lost and because of this it was recommended that a colony should be established from insects captured in the region of the type area and that their description should serve as the basis for future descriptions. It was pointed out that there is a lack of uniformity in the naming of closely related American sand flies and that some of the differences between populations of Lu. longipalpis are greater than those between accepted species. The majority of the participants agreed that the populations that have been defined in the literature as sibling species should be named.

During the III Workshop on Genetics and Molecular Biology of Tropical Diseases Vectors (EntoMol 3 - http:// www.cpqam.fiocruz.br/entomol3) held in Recife, Brazil, at the Instituto Aggeu Magalhães-Fiocruz, the organizers decided to convene a satellite meeting to discuss the importance of giving valid taxonomic names to sand flies belonging to the Lutzomyia longipalpis complex. Although some key experts in the area were not present, it was considered that it would be important to hear the opinions of those who where there and who are involved in different aspects of the biology of this sand fly.

The pioneering work of Richard Ward and his group (Ward et al. 1983, 1988) drew attention to the complex population structure of $\mathrm{Lu}$. longipalpis sensu lato and of the existence of reproductively isolated populations. By 1993, Greg Lanzaro's group concluded (Lanzaro et al. 1993) that Lu. longipalpis was a species complex composed of at least three species. Females of a Venezuelan population where found to have distinctive morphological characters and for this reason they where named Lutzomyia pseudolongipalpis (Arrivillaga \& Feliciangeli 2001). This species is also genetically different to other

Financial support: CNPq, FACEPE, FIOCRUZ, UFPE, FAPESP + Corresponding authors: sinval@cpqam.fiocruz.br; jeffreyj@usp.br Received 18 June 2009

Accepted 10 November 2009 populations and has male pheromones that are unique (Hamilton et al. 2005, Watts et al. 2005). Analysis of characters such as pheromones (Hamilton et al. 1996, 2005), the copulation song genes period and cacophony (Bauzer et al. 2002) and variation at microsatellite loci (Maingon et al. 2003) all added weight to the concept that $\mathrm{Lu}$. longipalpis s.l. is a species complex . A review published in 2007 (Bauzer et al. 2007) questioned if Brazilian populations of $L u$. longipalpis were a complex or a single species and concluded that " $\mathrm{Lu}$. longipalpis in Brazil is one example of a complex of incipient vector species showing perhaps a similar level of complexity presented by Anopheles gambiae s.s. in Africa”.

One of the most extensive analyses of Brazilian $L u$. longipalpis populations was published after the meeting by Araki et al. (2009). These authors performed a combined analysis of different characters (molecular polymorphism of selected genes, copulation song patterns and pheromone types) and confirmed the occurrence of sympatric sibling species in new localities. They conclude that speciation is occurring within the Lu. longipalpis complex and found populations that had different copulation songs but the same pheromone. This emphasized the danger in using one character to determine reproductive isolation.

So far no clear links have been found (Maingon et al. 2008) between visceral leishmaniasis transmission and the cryptic species of the Lu. longipalpis but the spread of the disease could be linked to vector selection in modified habitats and the precise identification of the populations in different geographical area is crucial to understanding the expansion of this disease. 
The above clearly shows that the literature supports the thesis that $L u$. longipalpis is a complex of species but that the number involved is undetermined (Araki et al. 2009). It was against this background that the discussion was based. The lack of morphological differences between the physiologically different species could be considered as a handicap in describing them formally. However, there is no reason why biological and biochemical characters cannot be used as they are for numerous trypanosomatid species. The presence of one or two pairs of abdominal spots prompted the first experiments (Ward et al. 1983) on the reproductive isolation of the complex. They showed that these spots were not reliable genetic markers as there was reduced fertilization between populations with the same number of spots. Recently it has been found that two and one spot populations from Estrela de Alagoas and Jaíba, Minas Gerais (MG) were found to belong to two sympatric sibling species (Araki et al. 2009). However, in the case of those from Estrela de Alagoas the copulation songs were different but the pheromones were the same. So there is evidence that under certain circumstances morphological characters are useful, although they may not be of value in defining a species since they are shared amongst sibling species.

The most recent publication on the subject (Araki et al. 2009) concluded that "it is still not clear how many species or incipient species of the L. longipalpis complex exist within Brazil”.

The discussion opened by drawing attention to the fact that there is often a delay in giving formal names to species that are initially defined by biological and chemical characters. Eunice Galati revised the circumstances that surrounded the original description (Lutz \& Neiva 1912) of the species and drew attention to the fact that the species was described on the basis of external characters, but that unfortunately the specimens used in this description no longer exist. This is not a unique problem and the type material for other sand flies such as Migonemyia migonei and Pintomyia fischeri has also been lost. In listing the characters that are used to describe sand fly species belonging to a complex she remarked that they have been used to synonymize species but subsequently used to separate them again (e.g. Nyssomyia neivai and Nyssomyia intermedia) (Marcondes 1996). However, she mentioned that morphological characters may not be sufficient to identify a species and biochemical ones (isoenzymes and pheromones) as well as karyotyping and mitochondrial DNA together with behaviour can distinguish valid taxonomic groups. The females of $L u$. longipalpis, Lutzomyia cruzi and Lutzomyia gaminarai are morphologically indistinguishable and are accepted species, however, the males can be distinguished. Similar situations occur amongst sand flies of the genus Psychodopygus. Based on this, Eunice Galati recommended that the morphology of specimens of both sexes from precisely defined capture sites should be studied more carefully as some morphological differences may have been overlooked. She emphasized that in the case of giving names the code of Zoological Nomenclature (International Commission on Zoological Nomenclature 1999) must be respected.
Subsequently, Reginaldo Brazil commented on the ecology of Lu. longipalpis in the city of Campo Grande, state of Mato Grosso do Sul, Brazil. He drew attention to its ample distribution in different biomes throughout the Americas and that this shows how it is capable of adapting to urban areas of city centers. Campo Grande is no exception to this and there is a population peak during the wet season and a close association with chicken coops (Oliveira et al. 2006). There is a clear connection between the number of flies and the number of human cases. Blood meal analysis showed that man is the principal source of food followed by chickens. Surprisingly dogs only represented $6 \%$ of the blood meals. Insecticide control reduced other species of sand flies but not $\mathrm{Lu}$. longipalpis. Based on these observations he recommended that control measures need to be evaluated in each area in order to determine which strategy is the most suitable rather than blindly globally applying general methods.

Gordon Hamilton discussed pheromones and the mating sounds produced by the males (copulation songs) that have to be positively recognized by the female for mating to occur. The co-evolution of these characters results in the genetic isolation of groups of individuals and is the major mechanism of speciation within a complex (Araki et al. 2009). Describing the pheromones and copulation songs in various populations that combine with each other is a complex exercise.

Jeffrey Shaw drew attention to the necessity of assessing the epidemiological importance of the different genetic groups. This can be done by examining biological characters, such as relative infectivity as well as host and ecological niche preferences of different genotypes. $\mathrm{Lu}$. longipalpis urban populations that are responsible for the transmission of the visceral leishmaniasis amongst dogs and man originated from sylvatic populations. Given this sylvatic origin it is important to verify their relationship to transmission amongst wild canids in the absence of domestic cycles. In São Paulo (SP), $L u$. longipalpis continues to advance towards the capital and now occurs as far south as Bauru (Cutolo et al. 2009, Troncarelli et al. 2009, unpublished observations). Isolated populations occur in other parts of the state close to MG (Mayo et al. 1998). It is important to determine the pheromones and copulation songs of these populations in order to understand how and why the sand fly is spreading. One possibility of its north-south expansion in SP is that it is being transported along the trunk roads between the major urban centers (Correa Antonialli et al. 2007), a situation reminiscent of the spread of Triatoma infestans. There is evidence that introgression amongst $\mathrm{Lu}$. longipalpis sympatric siblings is greater than between Ny. intermedia and Nyssomyia whitmani (Mazzoni et al. 2008).

Valdir Balbino considered that the number of original scientific publications and revisions on An. gambiae complex were very similar to those of the L. longipalpis complex and cited the importance of determining the ancestral characters that would be more efficient in understanding the phylogeny and classification of the complex. Karyotype (G-banding), isoenzymes and 
pheromones studies indicate that $L u$. pseudolongipalpis is more distant than other members of the complex that have so been examined (Watts et al. 2005). He drew attention to the necessity of developing new genetic markers for such studies.

The above comments were used as basis for an open discussion amongst the participants and the major points are summarized as follows. One reservation was that without adequate characterization of neotype material, on the scale already presently available in the literature that it would be unwise to name the sibling species. However, according to the Zoological Nomenclatures Code, this is not a problem. If one sibling species proves to be identical with the neotype material in the future its name simply becomes a synonym. It was suggested that priority should be given to multidisciplinary studies on individuals collected in the type area and that a colony established from flies captured in the type area would facilitate these studies. The general lack of sand fly colonies in Brazilian research institutions is a reflection of the difficulties involved in their maintenance. José Carlos Miranda has extensive experience in both the field and laboratory and has successfully maintained colonies of this fly. He agreed to try and establish a colony from the type area providing he could get the logistical support.

Concern was voiced that the "species" is adapting to the intra and peridomiciliary habitats in many regions, citing the new focus of visceral leishmaniasis in Araguaína, Tocantins as being a good example of this (Andrade Filho et al. 2001) and of the importance of comparing peri and intradomiciliary populations. In respect to this it was emphasized that the naming of genetic groups should precede epidemiological studies and that it was important to focus studies in areas where sympatric populations are found such as Sobral.

It was also proposed that collections should be made in various locations paying special attention to populations found in caves, which are considered as being the most primitive members of the complex. It was suggested that description methods should be standardized and that this could involve a network of research workers. Some thought that it was doubtful if giving names would be useful but it was pointed out that they would help in the logical organization of the complex as well as facilitating communication amongst public health workers and other academic groups who were not specialists in the area. An example of this latter point is that the naming of sibling species of the gambiae complex species greatly improved the transmission of information about their relative vectorial importance.

Although there was a divergence in opinions as to the desirability of giving names to genetically distinct populations that have been defined in the literature it was unanimously agreed that priority must be given to distinctions based on pairs of pheromones and copulation songs that are consistent for a population. However, to many of the participants it was incoherent that in the literature there are continuous references to "sympatric species of the longipalpis complex", but these are never given names. Why? In spite of the arguments and evidence, three participants were not convinced that giv- ing names would be useful while the other 15 considered that it was important that these "species" are named.

The meeting was attended by the following 18 participants: Alda Lima Falcão, Carlos Brisola Marcondes, Cezar Costa Junior, Edelberto Santos Dias, Elizabeth Rangel, Eunice Galati, Felipe Dantas-Torres, Fernando Monteiro, Gordon Hamilton, Jeffrey Shaw, José Carlos Miranda, José Dilermando Andrade, Paul Ready, Paulo Pimenta, Reginaldo Brazil, Sinval Brandão Filho, Valdir Balbino and Wanderli Taddei.

\section{REFERENCES}

Andrade Filho JD, Valente MB, de Andrade WA, Brazil RP, Falcão AL 2001. Flebotomineos do estado de Tocantins, Brasil (Diptera: Psychodidae). Rev Soc Bras Med Trop 34: 323-329.

Araki AS, Vigoder FM, Bauzer LG, Ferreira GE, Souza NA, Araujo IB, Hamilton JG, Brazil RP, Peixoto AA 2009. Molecular and behavioral differentiation among Brazilian populations of Lutzomyia longipalpis (Diptera: Psychodidae: Phlebotominae). PLoS Negl Trop Dis 3: e365.

Arrivillaga JC, Feliciangeli MD 2001. Lutzomyia pseudolongipalpis: the first new species within the longipalpis (Diptera: Psychodidae: Phlebotominae) complex from La Rinconada, Curarigua, Lara state, Venezuela. J Med Entomol 38: 783-790.

Bauzer LG, Gesto JS, Souza NA, Ward RD, Hamilton JG, Kyriacou CP, Peixoto AA 2002. Molecular divergence in the period gene between two putative sympatric species of the Lutzomyia longipalpis complex. Mol Biol Evol 19: 1624-1627.

Bauzer LG, Souza NA, Maingon RD, Peixoto AA 2007. Lutzomyia longipalpis in Brazil: a complex or a single species? A mini-review. Mem Inst Oswaldo Cruz 102: 1-12.

Correa Antonialli SA, Torres TG, Paranhos Filho AC, Tolezano JE 2007. Spatial analysis of American visceral leishmaniasis in Mato Grosso do Sul state, Central Brazil. J Infect 54: 509-514.

Cutolo AA, Camargo DA, Von Zuben C J 2009. Novos registros de Lutzomyia longipalpis (Lutz \& Neiva, 1912) (Diptera: Psychodidae) na região Centro-Leste do estado de São Paulo, Brasil. Rev Bras Parasitol Vet 18: 62-65.

Hamilton JG, Maingon RD, Alexander B, Ward RD, Brazil RP 2005. Analysis of the sex pheromone extract of individual male Lutzomyia longipalpis sand flies from six regions in Brazil. Med Vet Entomol 19: 480-488.

Hamilton JG, Ward RD, Dougherty MJ, Maignon R, Ponce C, Ponce E, Noyes H, Zeledon R 1996. Comparison of the sex-pheromone components of Lutzomyia longipalpis (Diptera: Psychodidae) from areas of visceral and atypical cutaneous leishmaniasis in Honduras and Cost Rica. Ann Trop Med Parasitol 90: 533-541.

International Commission on Zoological Nomenclature 1999. International Code of Zoological Nomenclature, The International Trust for Zoological Nomenclature, London, $306 \mathrm{pp}$.

Lanzaro GC, Ostrovska K, Herrero MV, Lawyer PG, Warburg A 1993. Lutzomyia longipalpis is a species complex: genetic divergence and interspecific hybrid sterility among three populations. Amer J Trop Med Hyg 48: 839-847.

Lutz A, Neiva A 1912. Contribuição para o conhecimento das espécies do gênero Phlebotomus existentes no Brasil. Mem Inst Oswaldo Cruz 4: 82-95.

Maingon RD, Ward RD, Hamilton JG, Bauzer LG, Peixoto AA 2008. The Lutzomyia longipalpis species complex: does population sub-structure matter to Leishmania transmission? Trends Parasitol 24: 12-17. 
Maingon RD, Ward RD, Hamilton JG, Noyes HA, Souza N, Kemp SJ, Watts PC 2003. Genetic identification of two sibling species of Lutzomyia longipalpis (Diptera: Psychodidae) that produce distinct male sex pheromones in Sobral, Ceará state, Brazil. Mol Ecol 12: 1879-1894.

Marcondes CB 1996. A redescription of Lutzomyia (Nyssomyia) intermedia (Lutz \& Neiva, 1912) and resurrection of L. neivai (Pinto, 1926) (Diptera: Psychodidae: Phlebotominae). Mem Inst Oswaldo Cruz 91: 457-462.

Mayo RC, Casanova C, Mascarini LM, Pignatti MG, Rangel O, Galati EA, Wanderley DM, Correa FM 1998. Flebotomíneos (Diptera: Psychodidae) de área de transmissão de leishmaniose tegumentar americana no município de Itupeva, região sudeste do estado de São Paulo, Brasil. Rev Soc Bras Med Trop 31: 339-345.

Mazzoni CJ, Araki AS, Ferreira GE, Azevedo RV, Barbujani G, Peixoto AA 2008. Multilocus analysis of introgression between two sand fly vectors of leishmaniasis. BMC Evol Biol 8: 141.

Oliveira AG, Galati EA, de Oliveira O, de Oliveira GR, Espindola IA, Dorval ME, Brazil RP 2006. Abundance of Lutzomyia longipalpis (Diptera: Psychodidae: Phlebotominae) and urban transmis- sion of visceral leishmaniasis in Campo Grande, state of Mato Grosso do Sul, Brazil. Mem Inst Oswaldo Cruz 101: 869-874.

Troncarelli MZ, Camargo JB, Machado JG, Lucheis SB, Langoni H 2009. Leishmania spp and/or Trypanosoma cruzi diagnosis in dogs from endemic and nonendemic areas for canine visceral leishmaniasis. Vet Parasitol, in press.

Ward RD, Phillips A, Burnet A, Marcondes CR 1988. The Lutzomyia longipalpis complex: reproduction and distribution. In MW Service (ed.), Biosystematics of haematophagus insects, Clarendon Press, Oxford, p. 257-269.

Ward RD, Ribeiro AL, Ready PD, Murtagh A 1983. Reproductive isolation between different forms of Lutzomyia longipalpis (Lutz \& Neiva), (Diptera: Psychodidae), the vector of Leishmania donovani chagasi Cunha \& Chagas and its significance to kala-azar distribution in South America. Mem Inst Oswaldo Cruz 78: 269-280.

Watts PC, Hamilton JG, Ward RD, Noyes HA, Souza NA, Kemp SJ, Feliciangeli MD, Brazil R, Maingon RD 2005. Male sex pheromones and the phylogeographic structure of the Lutzomyia longipalpis species complex (Diptera: Psychodidae) from Brazil and Venezuela. Amer J Trop Med Hyg 73: 734-743. 